\title{
Ultra-thin crystalline silicon films produced by plasma assisted epitaxial growth on silicon wafers and their transfer to foreign substrates $^{\star}$
}

\author{
M. Moreno ${ }^{\mathrm{a}}$ and P. Roca i Cabarrocas \\ Laboratoire de Physique des Interfaces et des Couches Minces, École Polytechnique, CNRS, Palaiseau, France
}

Received: 22 April 2010 / Accepted: 28 July 2010

Published online: 5 October 2010

\begin{abstract}
We have developed a new process to produce ultra-thin crystalline silicon films with thicknesses in the range of $0.1-1 \mu \mathrm{m}$ on flexible substrates. A crystalline silicon wafer was cleaned by $\mathrm{SiF}_{4}$ plasma exposure and without breaking vacuum, an epitaxial film was grown from $\mathrm{SiF}_{4}, \mathrm{H}_{2}$ and $\mathrm{Ar}$ gas mixtures at low substrate temperature $\left(T_{\text {sub }} \approx 200{ }^{\circ} \mathrm{C}\right)$ in a standard RF PECVD reactor. We found that $\mathrm{H}_{2}$ dilution is a key parameter for the growth of high quality epitaxial films and modification of the structural composition of the interface with the c-Si wafer, allowing one to switch from a smooth interface at low hydrogen flow rates to a fragile one, composed of hydrogen-rich micro-cavities, at high hydrogen flow rates. This feature can be advantageously used to separate the epitaxial film from the crystalline Si wafer. As a example demonstration, we show that by depositing a metal film followed by a spin-coated polyimide layer and applying a moderate thermal treatment to the stack, the fragile interface breaks down and allows one to obtain an ultrathin crystalline wafer on the flexible polyimide support.
\end{abstract}

\section{Introduction}

Over the past twenty years, considerable efforts have been devoted to producing thin crystalline silicon films for micro-electronics and photovoltaic applications. The main motivation remains a reduction of the necessary amount of high grade crystalline silicon (c-Si) and therefore a reduction of device fabrication costs. For instance, very high efficiencies in heterojunction solar cells have been demonstrated (17-22\%), fabricated on thin c-Si substrates $(50-100 \mu \mathrm{m})[1,2]$ and so the goal of further reducing the c-Si wafer thickness is still a strong driving force for cost reduction.

Various approaches have been used to produce lowcost ultra-thin c-Si wafers; however, some of them involve high temperature steps (increasing the fabrication cost). Some of the most reliable approaches are: (i) cutting thin wafers and thinning them down by chemical mechanical polishing; (ii) growing thin c-Si films by LPCVD on a seed layer; (iii) annealing macroporous arrays formed on a crystalline silicon wafer (also referred to as silicon on nothing $[3,4])$; and (iv) the "smart cut" [5-7] and ion cutting porcesses [8-12].

Smart cut and ion cutting processes are proven methods to transfer a thin silicon film from a wafer to another

\footnotetext{
* This article has been previously published in PV Direct, the former name of EPJ Photovoltaics.

a Address for correspondence: National Institute for Astrophysics, Optics and Electronics, INAOE, Puebla, Mexico; e-mail: mmoreno@inaoep.mx
}

substrate, which generally is a second wafer, in which a thin $\mathrm{SiO}_{2}$ film has been deposited (to form a silicon on insulator wafer). Those techniques employ $\mathrm{H}^{+}$ion implantation in a c-Si wafer (at doses between $10^{16}-10^{17} \mathrm{H} / \mathrm{cm}^{2}$ ) in order to create defects (micro-cavities) at some depth from the wafer surface. In this way, it is possible to form a very thin c-Si film $(0.3-1 \mu \mathrm{m})$ separated from the thick wafer by a highly defective and therefore weak layer. A hydrophilic wafer bonding is performed with a second wafer and thermal processes are applied (at $650-1000{ }^{\circ} \mathrm{C}$ ) in order to transfer the thin c-Si film from the thick wafer to the receptor substrate and to strengthen the chemical bonds.

Another approach to obtaining thin c-Si films for PV applications $[13,14]$ consists of producing a porous film (1 $\mu \mathrm{m}$ thick) on the surface of a c-Si wafer by electrochemical anodisation in a $\mathrm{HF}$ solution. An annealing is made at high temperature $\left(1000{ }^{\circ} \mathrm{C}\right)$ for densification of the porous film and an epitaxial layer $(\sim 50 \mu \mathrm{m}$ thick $)$ is deposited by Liquid Phase Epitaxy (LPE) [13] and Vapor Phase Epitaxy (VPE) [14]. Finally the epitaxial layer is waxed to a glass substrate and is removed from the c-Si wafer by an immersion in a wet solution.

The disadvantages of these processes are the large number of steps involved, the high temperatures used $\left(\sim 1000{ }^{\circ} \mathrm{C}\right)$, the necessity of a second substrate, the wet chemical steps involved and the fact that $\mathrm{H}^{+}$implantation LPE and VPE are not standard techniques in a PV factory. 
We have studied an alternative method to produce lowcost ultra-thin c-Si films without the necessity of using wet chemical steps, a second wafer, $\mathrm{H}^{+}$implantation, LPE or VPE. We have developed a completely dry process to etch the native oxide from a c-Si wafer using a $\mathrm{SiF}_{4}$ plasma in a standard PECVD reactor [15], and immediately without breaking the vacuum, to grow an epitaxial silicon film at low substrate temperature $\left(\sim 200^{\circ} \mathrm{C}\right)$ from a $\mathrm{H}_{2}, \mathrm{SiF}_{4}$, and Ar gas mixture.

We present a systematic study on the effect of $\mathrm{H}_{2}$ dilution on the quality of the epitaxial Si films as well as on the quality of the interface with the c-Si wafer. We found that by optimizing the $\mathrm{H}_{2}$ gas flow rate it is possible to obtain very highly crystalline films, and moreover, to control the interface quality from a smooth one to a highly defective interface, mainly composed of micro-cavities.

Finally, we developed a simple process to remove the epitaxial film from the c-Si wafer, which consists of the deposition of a thin metal layer plus polyimide over the epitaxial film, followed by a thermal annealing treatment (at $\sim 450{ }^{\circ} \mathrm{C}$ ). As a consequence the stack composed of polyimide/metal/epitaxial film is separated from the c-Si wafer, resulting in a thin film of c-Si on a flexible substrate which functions as a mechanical support.

\section{Experiments}

The system used for the epitaxial growth is a standard capacitively coupled RF glow discharge PECVD reactor, and the substrates used were $\langle 100\rangle \mathrm{FZ}$ n-type double side polished c-Si wafers of resistivity $1-5 \Omega \mathrm{cm}$. The processes were performed at a substrate temperature of $200^{\circ} \mathrm{C}$. After loading the wafers in the reactor and attaining a base pressure of $1 \times 10^{-6} \mathrm{mbar}$, the native oxide on the c-Si wafers was removed through exposure to a $\mathrm{SiF}_{4}$ plasma for 5 minutes, with the following optimized conditions: an $\mathrm{RF}$ power of $0.1 \mathrm{~W} / \mathrm{cm}^{2}$ and pressure of $30 \mathrm{mTorr}$. Immediately after this step, and without breaking the vacuum, the epitaxial film was grown from a $\mathrm{SiF}_{4}, \mathrm{Ar}$ and $\mathrm{H}_{2}$ gas mixture for 10 minutes, with a RF power density of $0.5 \mathrm{~W} / \mathrm{cm}^{2}$ and a total pressure of 2.2 Torr. $\mathrm{H}_{2}$ dilution was studied in order to observe its effect on the epitaxial film crystallinity, and therefore the $\mathrm{H}_{2} / \mathrm{SiF}_{4}$ gas ratio was varied in a wide range from 0.33 to $20\left(\mathrm{SiF}_{4}=3 \mathrm{sccm}\right.$, while $\mathrm{H}_{2}=1-60 \mathrm{sssm}$ ).

High Ar dilution ( $\mathrm{Ar}=80 \mathrm{sccm})$ was used to increase the $\mathrm{SiF}_{4}$ gas dissociation and consequently the growth rate. It has been demonstrated in our previous work $[16,17]$, that Ar improves the dissociation in both $\mathrm{SiF}_{4}$ and $\mathrm{SiH}_{4}$ plasmas, and therefore stimulates nanocrystal growth in the plasma. The improvement of the crystalline structure is related to the enhancement of the contribution of nanocrystals to the film growth. Also, it has been experimentally observed that higher large grain fractions [16] are present in $\mu \mathrm{c}-\mathrm{Si}$ films deposited from $\mathrm{SiF}_{4}+\mathrm{Ar}+\mathrm{H}_{2}$ than in those deposited from $\mathrm{SiH}_{4}+\mathrm{Ar}+\mathrm{H}_{2}$.

It has been demonstrated that in-situ spectroscopic UV-Visible ellipsometry is an excellent tool to characterize the composition of thin films such as microcrystalline silicon [16-19]. An in-situ UV-Visible spectroscopic ellipsometer (Jobin Yvon - MWR UVISEL) was used to measure the imaginary part of the pseudo-dielectric function $(\operatorname{Im}[\varepsilon])$ of the epitaxial films deposited on the c-Si wafer at various stages of the process. We used this technique to optimize the plasma cleaning conditions and as well the epitaxial silicon film growth. The thickness of the layers and their composition were determined by modeling the ellipsometry data using the Bruggemann effective medium approximation [16-19].

In order to study the chemical composition of the films, particularly of the interface layer, we performed Secondary Ion Mass Spectroscopy (SIMS) analysis of some samples. Moreover, a quadrupole mass spectrometer (QMS PRISMA 80) was used to measure the hydrogen effusing from the samples when submitted to an annealing in an oven under high vacuum $\left(\sim 10^{-7}\right.$ mbar $)$. The thermal ramp used was $10^{\circ} \mathrm{C} / \mathrm{min}$ from room temperature up to $800^{\circ} \mathrm{C}$.

A procedure to remove the epitaxial layer from the c-Si wafer was developed, which consists of depositing a thin film of chromium (150 nm thick) on the epitaxial layer by thermal evaporation, followed by the spin coating of a polyimide film and a curing step at $280{ }^{\circ} \mathrm{C}$. The sample is then annealed for half an hour at $450{ }^{\circ} \mathrm{C}$ under vacuum $\left(\sim 10^{-5}\right.$ mbar). This annealing step is sufficient to fragilize the porous interface layer and to delaminate the polyimide/Cr/epitaxial layer from the crystalline silicon wafer. The polyimide provides a good mechanical support for the epitaxial film. Finally, Raman spectroscopy was used to analyze the crystallinity of the epitaxial films on the foreign substrate.

\section{Results and discussion}

\subsection{Epitaxial films}

We measured in-situ the imaginary part of the pseudodielectric function $\operatorname{Im}[\varepsilon]$ of $\mathrm{c}-\mathrm{Si}$ in the energy range of 1.5-4.7 eV, before plasma cleaning, after native $\mathrm{SiO}_{2}$ etching, and after the growth of the epitaxial films with various $\mathrm{H}_{2}$ flow rates. Figure 1 shows $\operatorname{Im}[\varepsilon]$ of four selected samples: (1) c-Si with native $\mathrm{SiO}_{2} ;(2)$ c-Si after the native $\mathrm{SiO}_{2}$ plasma etching; (3) epitaxial-Si film growth with $\mathrm{SiF}_{4} / \mathrm{H}_{2}=3 / 1 \mathrm{sccm}$; and (4) epitaxial-Si film growth with $\mathrm{SiF}_{4} / \mathrm{H}_{2}=3 / 3 \mathrm{sccm}$ (in cases 3 and $4 \mathrm{Ar}=80 \mathrm{sccm}$ ).

As one can see in Figure 1, when the native $\mathrm{SiO}_{2}$ is present on the c-Si surface, the intensity of $\operatorname{Im}[\varepsilon]$ at $4.2 \mathrm{eV}$ $\left(E_{2}\right)$ has an amplitude around $E_{2} \approx 36$, but it increases to $E_{2} \approx 43$ when the native $\mathrm{SiO}_{2}$ is etched by the $\mathrm{SiF}_{4}$ plasma. After the deposition of an epitaxial film at low $\mathrm{H}_{2}$ flow rate $\left(\mathrm{H}_{2}=1 \mathrm{sccm}\right)$, one can see that the $\operatorname{Im}[\varepsilon] \mathrm{spec}-$ trum has the same shape as that of the bare c-Si wafer, suggesting that the deposited film has the same structural composition and quality as the c-Si wafer (this is corroborated from the modeling of the $\operatorname{Im}[\varepsilon]$ spectrum). However, when the $\mathrm{H}_{2}$ flow rate is increased up to $3 \mathrm{sccm}$, interference fringes appear in the $\operatorname{Im}[\varepsilon]$. These interference fringes, in the energy range from $1.5-3 \mathrm{eV}$, provide 
M. Moreno and P. Roca i Cabarrocas: Ultra-thin crystalline silicon films produced by plasma...

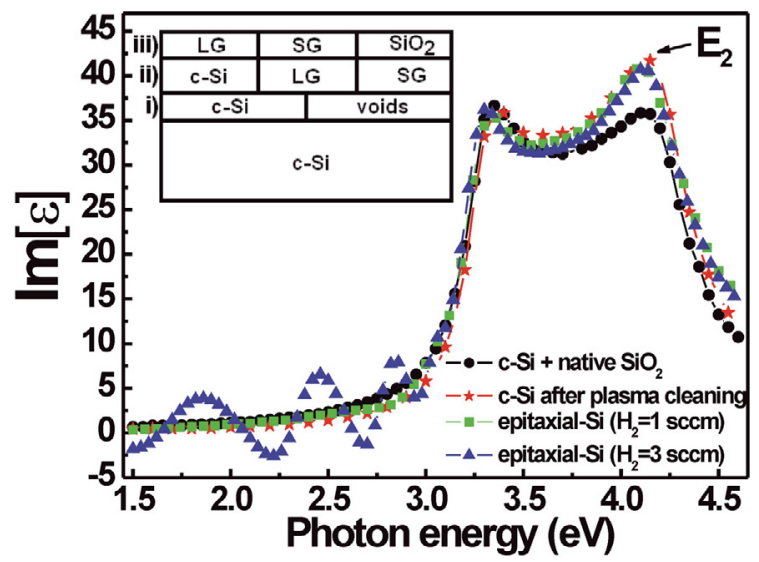

Fig. 1. (Color online) Imaginary part of the pseudo-dielectric function $\operatorname{Im}[\varepsilon]$ of different samples: c-Si with native $\mathrm{SiO}_{2}, \mathrm{c}-\mathrm{Si}$ after native $\mathrm{SiO}_{2}$ etching, and epitaxial-Si films grown with hydrogen flow rates of $1 \mathrm{sccm}$ and $3 \mathrm{sccm}$. The inset shows the optical model used to analyze the epitaxial films.

a signature of the formation of a porous interface between the c-Si wafer and the epitaxial layer. This is illustrated by the insert of Figure 1, showing the optical model used to fit the experimental data. As one can see, the film is generally composed of 3 layers:

(i) A thin interface layer between the epitaxial film and the c-Si substrate composed of monocrystalline silicon (c-Si) and voids [20], of thickness in the range of 0-90 $\AA$ (depending on $\mathrm{H}_{2}$ dilution).

(ii) A bulk layer of thickness in the range of 900-1700 (the deposition time for all the films were 10 minutes, however, as shown below, the deposition rate depends on the hydrogen flow rate). The layer is composed of a mono crystalline silicon (c-Si) fraction, a large grain (LG) fraction and a small grain (SG) fraction. The small grains have a size in the range of $1-10 \mathrm{~nm}$, while the large grains have a size in the range of $10-100 \mathrm{~nm}$.

(iii) A surface roughness characterized by a thin layer composed of a large grain (LG) fraction, a small grain (SG) fraction and $\mathrm{SiO}_{2}$. The thickness of the surface roughness layer is in the range of $0-50 \AA$ (depending on the $\mathrm{H}_{2}$ dilution). The $\mathrm{SiO}_{2}$ fraction in the surface layers may be related to a small amount of oxygen in the deposition chamber.

The results of modeling the ellipsometric spectra of a series of films grown with a wide range of $\mathrm{H}_{2}$ flow rates $(1-60 \mathrm{sccm})$ are shown in Figure 2. Figure 2a shows the deposition rate and composition of the bulk epitaxial layers as a function of $\mathrm{H}_{2}$ flow rate. At low $\mathrm{H}_{2}$ flow rate $\left(\mathrm{H}_{2}=1 \mathrm{sccm}\right)$ the deposition rate is around $2 \AA / \mathrm{s}$, however when $\mathrm{H}_{2}$ flow rate increases, the deposition rate also increases, with a maximum close to $3 \AA / \mathrm{s}$ (when $\mathrm{SiF}_{4}=$ $\mathrm{H}_{2}=3 \mathrm{sccm}$ ). Further increase in $\mathrm{H}_{2}$ flow rate resulted in a decrease of the deposition rate. In Figure 2a we can also see that the bulk layer has a high mono crystalline fraction (c-Si) of 80-95\%, a small grain (SG) fraction of $5-20 \%$ and large grain (LG) fraction of $1-5 \%$.

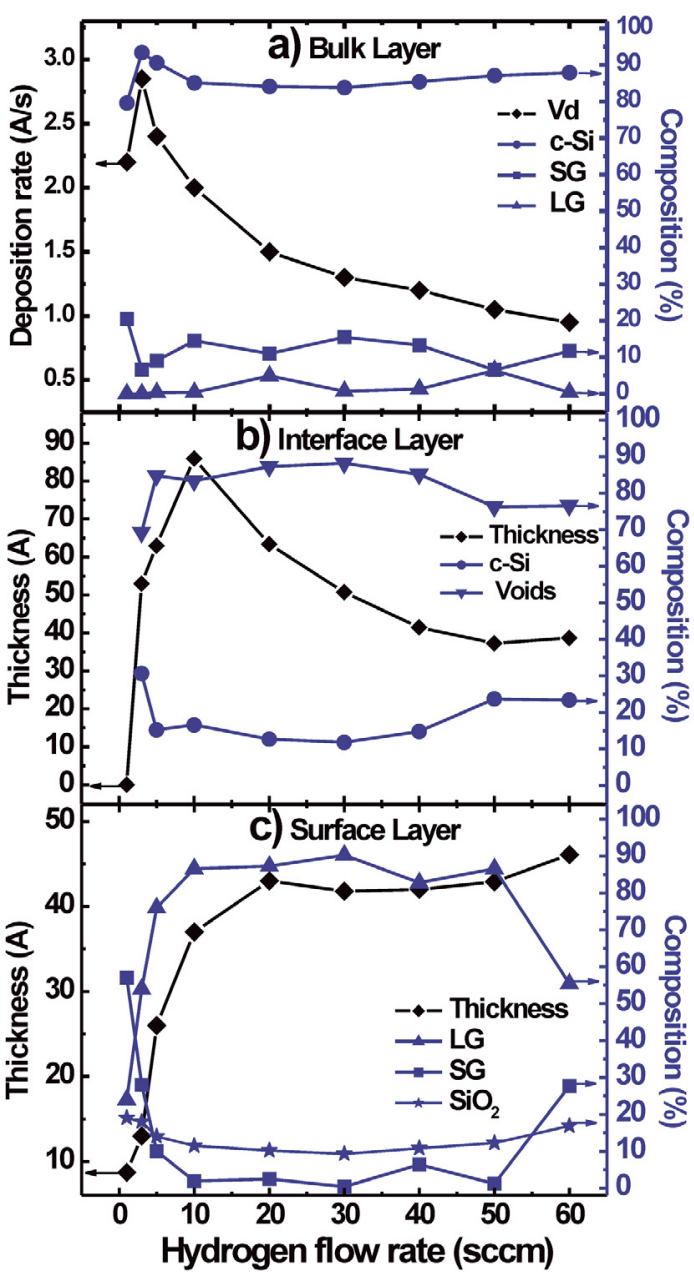

Fig. 2. (Color online) Results of modeling the ellipsometry spectra of the epitaxial films grown from $\mathrm{SiF}_{4}-\mathrm{Ar}-\mathrm{H}_{2}$ mixtures as a function of the hydrogen flow rate, showing (a) the deposition rate and composition of the bulk, the thickness and composition of (b) the interface and (c) surface roughness layers.

Interestingly, the highest monocrystalline fraction (c-Si $\sim 95 \%$ ) was obtained for the film deposited at the highest deposition rate. We believe that there is a strong relationship between the deposition rate and the crystallinity of a film. For certain deposition conditions, there is a greater dissociation of the gaseous species, improving the deposition rate. At higher deposition rate, oxygen incorporation in the film is reduced, and the film crystallinity improved.

Figure $2 \mathrm{~b}$ shows the thickness of the interface layer as a function of $\mathrm{H}_{2}$ flow rate. At low $\mathrm{H}_{2}$ flow rate $\left(\mathrm{H}_{2}=\right.$ $1 \mathrm{sccm}$ ) there is no interface layer. However when the $\mathrm{H}_{2}$ flow rate increases, an interface layer appears and reaches a maximum in thickness $(\sim 85 \AA)$ when $\mathrm{H}_{2}=10 \mathrm{sccm}$. A further increase in $\mathrm{H}_{2}$ dilution results in a decrease of the layer thickness. The reason for such behavior may result from a trade off between deposition rate and the hydrogen desorption from the growing film [21]. In Figure $2 \mathrm{~b}$ also is shown the structural composition of the interface layer as a function of $\mathrm{H}_{2}$ flow rate. As one can see, the interface 


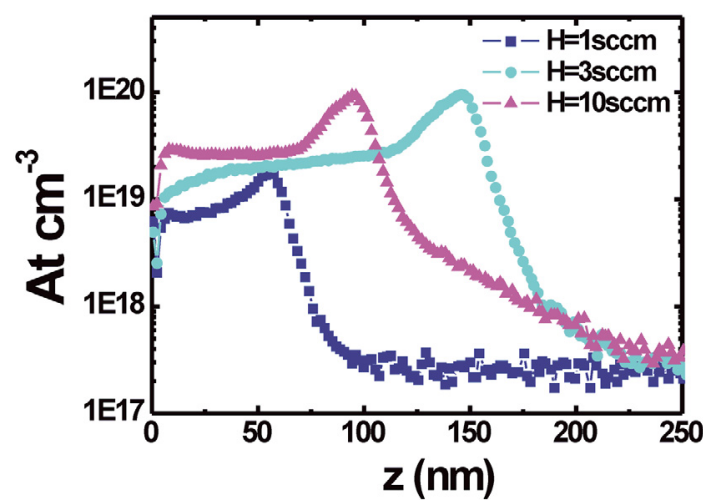

Fig. 3. (Color online) Hydrogen depth profiles measured by SIMS for epitaxial films grown with 1, 3 and $10 \mathrm{sccm}$ of hydrogen in the $\mathrm{SiF}_{4}-\mathrm{Ar}-\mathrm{H}_{2}$ gas mixture.

layer is mainly composed of voids (around 80\%) and a small amount of c-Si (around 20\%).

Figure 2c shows the surface roughness of the epitaxial films as a function of the $\mathrm{H}_{2}$ dilution. It is clear that the roughness of the films increases with the $\mathrm{H}_{2}$ flow rate from $\sim 9 \AA$ (at $\left.\mathrm{H}_{2}=1 \mathrm{sccm}\right)$ to $\sim 45 \AA$ (at $\left.\mathrm{H}_{2}=60 \mathrm{sccm}\right)$. This increase in surface roughness can be related to the enhanced etching at high hydrogen flow rates. The structural composition of the surface roughness layer is also shown in the figure, where one can see that the $\mathrm{SiO}_{2}$ fraction is almost independent of the $\mathrm{H}_{2}$ flow rate.

To support the ellipsometry results indicating the presence of an interface layer, SIMS analysis were performed on the epitaxial films. Figure 3 shows the hydrogen depth profiles for the films deposited with 1, 3 and $10 \mathrm{sccm}$ of hydrogen. The results show that the increase in hydrogen flow rate during deposition results in an increase of the hydrogen incorporated in the epitaxial films (from $6 \times 10^{18} \mathrm{~cm}^{-3}$ for the film deposited with $1 \mathrm{sccm}$ of $\mathrm{H}_{2}$ up to $3 \times 10^{19} \mathrm{~cm}^{-3}$ for the film deposited with $10 \mathrm{sccm}$ of $\mathrm{H}_{2}$ ), thus suggesting a better crystallinity at $1 \mathrm{sccm}$. Moreover a strong accumulation of hydrogen is observed at the interface between the epitaxial film and the crystalline substrate, with a broader peak for the samples deposited with 3 and $10 \mathrm{sccm}$, which is consistent with the thicker interface layer deduced from the ellipsometry measurements (see Fig. 2b).

Further support for the presence of a porous and hydrogen rich interface layer is given by the exodiffusion spectra shown in Figure 4. The spectra have been normalized with respect to the volume of the films in order to provide a relative comparison of the hydrogen desorbed. As one can see, the film grown with the smallest $\mathrm{H}_{2}$ flow rate $\left(\mathrm{H}_{2}=1 \mathrm{sccm}\right)$ shows the lowest integrated area of the curve, which indicates that the amount of $\mathrm{H}_{2}$ is small. However, when the $\mathrm{H}_{2}$ flow rate used for the deposition of the films is increased, the integrated area of the exodiffusion spectra increases as well and reaches a maximum for a $\mathrm{H}_{2}$ flow rate of $10 \mathrm{sccm}$. A further increase in the $\mathrm{H}_{2}$ flow rate results in a decrease of the integrated area. The difference in the effusing molecular $\mathrm{H}_{2}$ from the films can be correlated to the presence of $\mathrm{H}_{2}$ trapped at the interface,

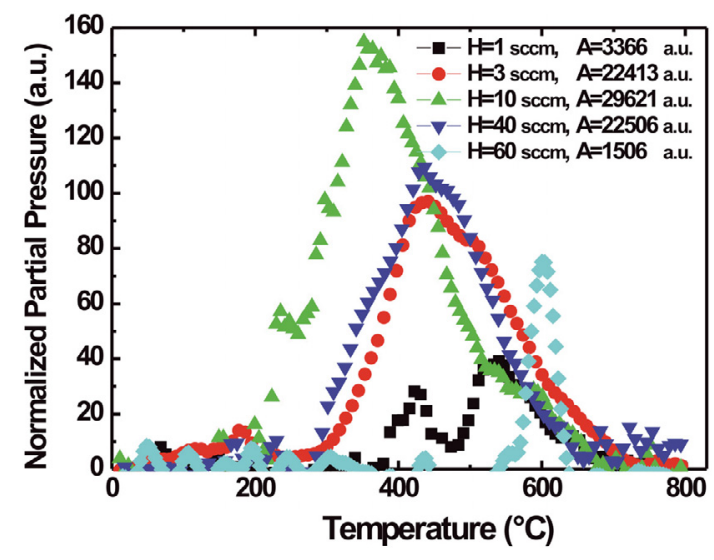

Fig. 4. (Color online) Hydrogen partial pressure measured by mass spectrometry for epitaxial layers grown with various hydrogen flow rates as a function of the annealing temperature.

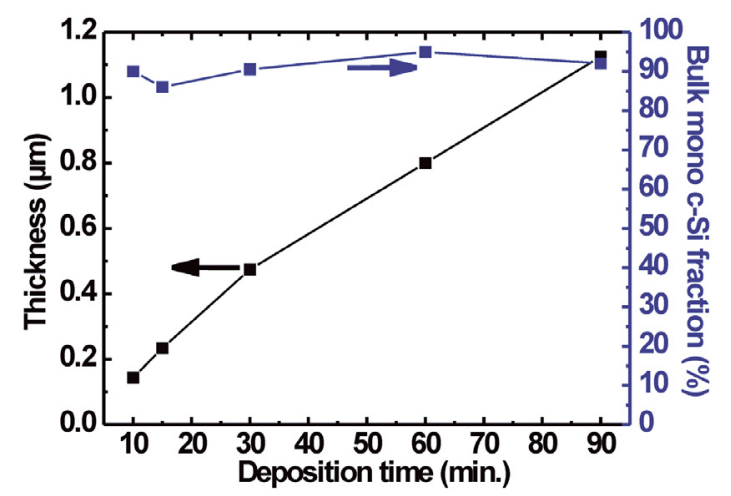

Fig. 5. (Color online) Dependence of the epitaxial film thickness and monocrystalline fraction on the deposition time.

in agreement with the SIMS results (Fig. 3). Note that the spectra of the different samples have a peak at different annealing temperatures, which is probably related to the structural composition of the films bulk (crystalline fraction) and interface layer composition [22,23]. While a detailed analysis of these spectra is out of the scope of this paper, these results are coherent with the strong differences in the hydrogen accumulation at the interface, as suggested by the modelling of the ellipsometry spectra and the SIMS measurements.

The above results demonstrate that epitaxial films with different quality of interface layer can be produced for thicknesses up to $200 \mathrm{~nm}$. However, for solar cell applications, thicker films are required. Therefore, in order to observe any dependence of the monocrystalline fraction of the epitaxial films on the layer thickness or deposition time, various epitaxial films were deposited for deposition times ranging from 10 to 90 minutes. Figure 5 shows that the mono crystalline fraction of the films is practically independent of the deposition time (and thickness) of the epitaxial films. A deposition of 10 minutes will result on a film of $1500 \AA$, corresponding to a deposition rate of $2.5 \AA / \mathrm{s}$ with a mono c-Si fraction of around $90 \%$; while a 
deposition of 90 minutes will result on a film of $1.1 \mu \mathrm{m}$ corresponding to a deposition rate of $2 \AA / \mathrm{s}$, with a mono c-Si fraction of around $92 \%$. From the above result we conclude that is possible to growth thicker epitaxial films, without a loss of crystalline fraction.

\subsection{Ultra-thin crystalline silicon film fabrication}

The above results have shown that we can grow epitaxial films at low substrate temperature $\left(\sim 200{ }^{\circ} \mathrm{C}\right)$ in a standard RF glow discharge reactor. Moreover, a fine tuning of the hydrogen flow rate allows one to produce films with a thin and highly porous interface layer which mimics the hydrogen layer produced by ion implantation in the Smart Cut process [5]. In particular, a $\mathrm{H}_{2}$ flow rate in the range of $3-10 \mathrm{sccm}$ results in an interface layer with a thickness of $6-9 \mathrm{~nm}$ and a void fraction of $\sim 85 \%$. Note that the void fraction deduced from spectroscopic ellipsometry is correlated with a high hydrogen content (SIMS and exodiffusion results).

Figure 6 shows the process developed to produce thin c-Si films. The c-Si wafer is placed inside the PECVD reactor without any previous cleaning. The native $\mathrm{SiO}_{2}$ is etched by $\mathrm{SiF}_{4}$ plasma [15] and the epitaxial c-Si film is deposited using the optimized conditions described above and in Section 3.1. The thickness of the film can be tailored according to the deposition time (as shown in Fig. 5). A chromium film of $150 \mathrm{~nm}$ is thermally evaporated on the epitaxial film followed by a deposition of a thin film of polymide by spin coating. A thermal annealing is performed at $450{ }^{\circ} \mathrm{C}$ under vacuum for half an hour. Finally the sample is cooled down and the vacuum is broken in order to produce the peeling of the c-Si film on a flexible substrate. This process allows to reuse the c-Si wafer, employing chemical polishing on the wafer surface, in order to remove defects from the surface and to facilitate the epitaxial grow.

Notice that the method presented above was performed with the equipment and materials available on our facilities. In fact any foreign substrate could be used for the transfer of the thin c-Si film. The only requirement is a strong adhesion between the foreign substrate and the ultrathin c-Si film.

The process described above (Fig. 6) was used to produce ultrathin crystalline silicon films as shown in Figure 7 . The picture in the inset shows an ultrathin crystalline silicon film of $\sim 1 \mathrm{~cm}^{2}$ on the polyimide foil, after being detached from the c-Si substrate. The Raman spectra of this ultrathin c-Si film (thickness of $0.5 \mu \mathrm{m}$ ) corresponds to the characteristic peak of c-Si at around $520 \mathrm{~cm}^{-1}$. Its full width at half maximum is $5 \mathrm{~cm}^{-1}$, which attests the high crystalline quality of the film, in good agreement with the ellipsometry spectra measured on the c-Si substrate before its detachment, from which a c-Si fraction of $95 \%$ was deduced.

This preliminary study, along with our previous work where we have demonstrated that it is possible to grow doped epitaxial films and to form a $\mathrm{P} / \mathrm{N}$ junction at $175^{\circ} \mathrm{C}$, leading to a functioning solar cell [24], provides a
Fabrication of ultra thin c-Si films

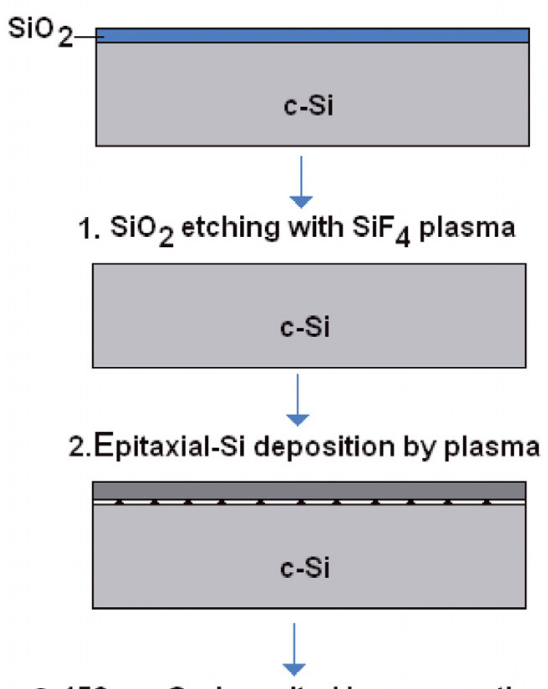

$3.150 \mathrm{~nm} \mathrm{Cr}$ deposited by evaporation

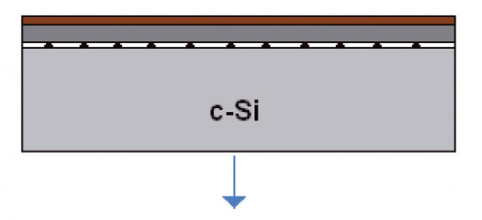

4. Polymide cured at $280^{\circ} \mathrm{C}$

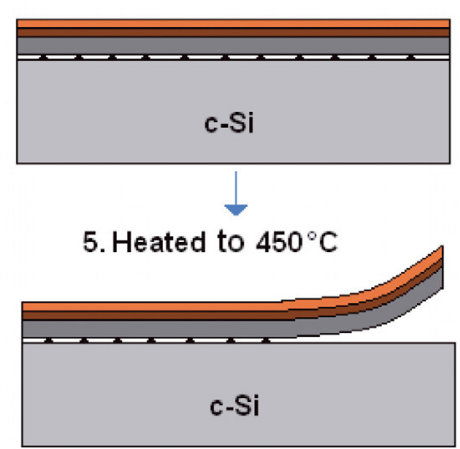

Fig. 6. (Color online) Schematic flow chart for the plasma assisted growth of ultrathin epitaxial films and their transfer to a polyimide support. Note that the maximum temperature of the process is $450{ }^{\circ} \mathrm{C}$.

new approach for producing ultra-thin c-Si solar cells with thicknesses of a few microns.

\section{Conclusions}

We have developed a new process to produce ultra-thin crystalline silicon substrates for low-cost microelectronic and PV devices. Epitaxial films have been deposited on $\langle 100\rangle$ c-Si wafers at low temperature $\left(200{ }^{\circ} \mathrm{C}\right)$ using a dry process to first etch the native $\mathrm{SiO}_{2}$, and then, without breaking the vacuum, a plasma deposition process using $\mathrm{SiF}_{4}-\mathrm{Ar}-\mathrm{H}_{2}$ mixtures. From the film characterization, we observed that by optimizing the $\mathrm{H}_{2} / \mathrm{SiF}_{4}$ flow rate ratio while using a high Ar dilution, it is possible to deposit films with a c-Si fraction as high as $95 \%$ and having an 


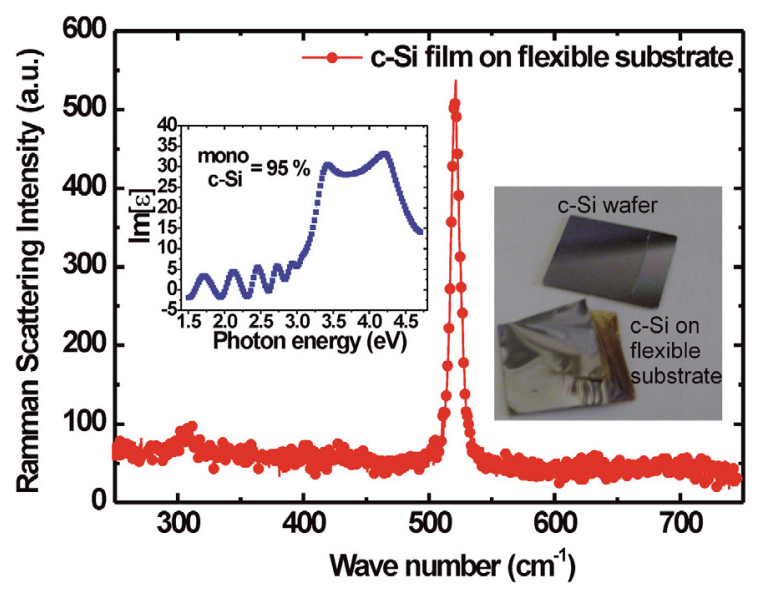

Fig. 7. (Color online) Raman spectrum of an ultra-thin c-Si film over a chromium/polyimide substrate. The left inset shows the $\operatorname{Im}[\varepsilon]$ spectra of the film grown on c-Si before its detachment from the c-Si wafer while the right inset shows the sample after being removed from the c-Si wafer.

interface layer thickness of up to $90 \AA$, mainly composed of hydrogen rich micro-cavities $(\sim 85 \%)$. This fragile interface allows the separation of the epitaxial film from the crystalline silicon wafer by applying a thermal annealing step at $450{ }^{\circ} \mathrm{C}$. As a result, crystalline silicon films were successfully obtained and transferred to chromium/polyimide flexible substrates. Finally, films up to $1 \mu \mathrm{m}$ thick could be epitaxially grown without any decrease in their crystalline fraction. This makes this process very promising for producing ultra-thin c-Si substrates of tailored thickness for micro-electronics and PV applications.

\section{References}

1. Y. Tsunomura, Y. Yoshimine, M. Taguchi, T. Baba, T. Kinoshita, H. Kanno, H. Sakata, E. Maruyama, M Tanaka, Sol. Energy. Mater. \& Sol. Cells 93, 670 (2009)

2. M. Reuter, W. Brendle, O. Tobail, J.H. Werner, Sol. Energy. Mater. \& Sol. Cells 93, 704 (2009)
3. I. Gordon, S. Vallon, A. Mayolet, G. Beaucarne, J. Poortmans, Sol. Energy. Mater. \& Sol. Cells 94, 381 (2010)

4. V. Depauw, I. Gordon, G. Beaucarne, J. Poortmans, R. Mertens, J.-P. Celis, J. Appl. Phys. 106, 1 (2009)

5. M. Bruel, Mat. Res. Innovat. 3, 9 (1999)

6. M. Bruel, Electron. Lett. 31, 1201 (1995)

7. H. Moriceau, F. Fournel, B. Aspar, J. Electron. Mater. 32, 829 (2003)

8. B. Terreault, Phys. Stat. Sol. (a) 204, 2129 (2007)

9. A. Giguere, B. Terreault, J. Appl. Phys. 102, 1 (2007)

10. O. Moutanabbir, A. Guiguere, B. Terreault, Appl. Phys. Lett. 84, 3286 (2004)

11. S. Igarashi, A.N. Itakura, M. Kitajima, Jpn J. Appl. Phys. 46, 7812 (2007)

12. N. Desroisers, B. Terreault, Appl. Phys. Lett. 89, 1 (2006)

13. S. Berger, S. Quoizola, A. Fave, A. Ouldabbes, A. Kamaniski, S. Perichon, N.-E. Chabane-Sari, D. Barbier, A. Laugier, Cryst. Res. Technol. 36, 1005 (2001)

14. J. Kraiem, O. Nichiporuk, P. Papet, A. Fave, A. Kaminski, E. Fourmond, J.-P. Boyeaux, P.-J. Ribeyron, A. Laugier, M. Lemiti, in Proc. of PVSEC-15, Shangai, China, 2005, pp. 746-747

15. M. Moreno, M. Labrune, P. Roca i Cabarrocas, Sol. Energy. Mater. \& Sol. Cells 94, 402 (2010)

16. Y. Djeridane, A. Abramov, P. Roca i Cabarrocas, Thin Solid Films 515, 7451 (2007)

17. A. Abramov, Y. Djeridane, R. Vanderhaghen, P. Roca i Cabarrocas, J. Non-Cryst. Solids 352, 964 (2006)

18. E.A. Irene, Thin Solid Films 233, 96 (1993)

19. P. Roca i Cabarrocas, S. Hamma, A. Hadjadj, J. Bertomeu, J. Andreu, Appl. Phys. Lett. 69, 529 (1996)

20. G.E. Jellison Jr., V.I. Merkulov, A.A. Puretzky, D.B. Geohegan, G. Eres, D.H. Lowndes, J.B. Caughman, Thin Solid Films 377-378, 68 (2000)

21. B. Kalache, A.I. Kosarev, R. Vanderhaghen, P. Roca i Cabarrocas, J. Appl. Phys. 93, 1262 (2003)

22. N. Pham, Y. Djeridane, A. Abramov, A. Hadjadj, P. Roca i Cabarrocas, Mat. Sci. Eng. B 159-160, 27 (2009)

23. N. Pham, A. Hadjadj, P. Roca i Cabarrocas, O. Jbara, F. Kail, Thin Solid Films 517, 6225 (2009)

24. M. Labrune, M. Moreno, P. Roca i Cabarrocas, Thin Solid Films 518, 2528 (2010) 